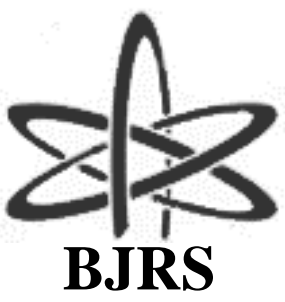

BRAZILIAN JOURNAL

$\mathrm{OF}$

RADIATION SCIENCES

05-01 (2017) 01-10

\title{
Attenuation coefficients for fibrous self-compacting concrete in the energy range of 50-3000keV
}

\author{
W.V. Bento ${ }^{\mathrm{a}, \mathrm{b}}$; L.A.M. Magalhães ${ }^{\mathrm{a}}$; C.C. Conti ${ }^{\mathrm{a}}$ \\ aIRD - Institute for Radioprotection and Dosimetry, CNEN/IRD, P.O. Box 37750, 22780-160 Rio de Janeiro, Brazil \\ ${ }^{b}$ ESIE - Specialized Instruction School, Defense Chemical, Biological and Nuclear, Brazilian Army, Rio de Janeiro, \\ Brazil \\ ccconti@ird.gov.br
}

\begin{abstract}
The fibrous self-compacting concrete is a high performance concrete with uniformly distributed iron fibers. Transmission measurements, with ${ }^{137} \mathrm{Cs}$ and ${ }^{60} \mathrm{Co}$ sources were performed for the attenuation coefficients determination for both ordinary and fibrous self-compacting concretes. The results were compared to each other and to the values found in the literature for ordinary concrete. The mass attenuation coefficient for the fibrous self-compacting concrete showed to be higher than those for ordinary concrete of about $5 \%$, depending on the gamma energy. However, it should be noted that the density of fibrous self-compacting concrete is higher than ordinary concrete, $2.4 \mathrm{~g} / \mathrm{cm}^{3}$ and $1.9 \mathrm{~g} / \mathrm{cm}^{3}$ respectively, increasing still further the difference in mass attenuation coefficient. In addition to that, by using Monte Carlo simulations, with MCNP5 Monte Carlo computer code, the data was extended to the 50-3000 keV gamma energy range.
\end{abstract}

Keywords: attenuation coefficient; concrete; self-compacting; shielding; Monte Carlo 


\section{INTRODUCTION}

Due to the increasing use of radioactive isotopes and linear accelerators in several fields of applications, such as industries, energy production and medical, there is also an increasing need to minimize the dose to the workers and to the public.

The facilities which deal with ionizing radiation of any type must comply with safety requirements and, at this stage, shielding calculations come into play. The large thickness of the concrete walls, ceiling and floor demand lots of space, especially in the cases of adjustments of an existing building or room for the new usage, imposing a great limitation in usable space for the equipment (Facure, 2007).

The use of lead can be, sometimes, an option, especially for smaller walls thickness demands. However, its cost is high and might be unsuitable, depending on the photon beam energy. On the other hand, ordinary concrete is a relatively inexpensive material, but needs larger thicknesses for the same shielding effect when compared to lead, due to its relatively lower attenuation coefficient.

Several studies have been carried out in order to determine the physical characteristics of building materials. Salinas et al. (2006) determined the mass attenuation coefficient for building materials commonly used in Brazil. Alan et al. (2001) reports that the mass attenuation coefficients for different soil samples and building materials in Bangladesh were determined. It was observed that heavy beach minerals, which are much denser than the other materials studied, showed photon attenuation coefficients higher than those for soil, sand and building materials. As it is well known, photon attenuation coefficients depend on the photon energy and the material's density (Akkurt et al, 2004).

This work presents data for a new type of concrete, the fibrous self-compacting concrete, which can meet something in between ordinary concrete and lead. Because of its higher attenuation coefficients and density than ordinary concrete, the use fibrous self-compacting concrete enables a reduction of walls thickness, without the cost and environmental impact risk created by the use of lead. 


\section{MATERIALS AND METHODS}

\subsection{Fibrous Self-compacting Concrete}

The fibrous self-compacting concrete is a high performance concrete with the special characteristic of having, in its structure, steel fibers distributed uniformly (Maragon, 2006 and 2009). Due to its rheological properties, this concrete presents a reduced amount of voids when compared to ordinary concrete, therefore, ensuring uniformity and allowing its use for shielding due to the higher density in addition to the embedded steel fibers.

The increase of steel fibers, which reduces the possibility of cracks in the structures, make it possible to build thinner walls with the same reliability of ordinary concrete and further enhancing the gamma shielding.

The fibrous self-compacting concrete sample used in this work was prepared at the Federal University of Rio de Janeiro with a thickness of 7cm (Maragon, 2006 and 2009). The density was calculated from several measurements and estimated to be $2.4 \mathrm{~g} / \mathrm{cm}^{3}$.

\subsection{Ordinary Concrete}

In order to evaluate the measuring setup and methodology used, transmission measurements were carried out with an ordinary concrete sample and the mass attenuation coefficient was compared to the values available in the literature. The density was calculated from several measurements of the ordinary concrete sample and estimated to be $1.9 \mathrm{~g} / \mathrm{cm}^{3}$.

\subsection{Gamma Sources}

Measurements were carried out with two sources: ${ }^{137} \mathrm{Cs}$ and ${ }^{60} \mathrm{Co}$, with activities of $0.42 \mathrm{TBq}$ and $0.0016 \mathrm{TBq}$ respectively. The sources were positioned at a distance of $3 \mathrm{~m}$ from the detector. The attenuation coefficients were determined for the energies of $662 \mathrm{keV}, 1172 \mathrm{keV}$ and $1332.5 \mathrm{keV}$. 


\subsection{Detector}

Experimental measurements were conducted using a 20\% HPGe portable detector. Both sources and detector were collimated to ensure a parallel photon bean in order to precisely account for the thickness of the material to be considered in the calculation. Transmission measurements were performed with those two sources, corresponding to three gamma energies for the mass attenuation coefficients calculation.

\subsection{Attenuation Coefficient $(\mu)$}

The linear attenuation coefficient for the different concrete types and energies were determined by the transmission measurement of collimated photon beam according to the following equation:

$$
I=I_{0} e^{-\iota x}
$$

Where:

$\mu=$ linear attenuation coefficient (in $\mathrm{cm}^{-1}$ );

$\mathrm{x}=$ thickness of the sample (in $\mathrm{cm})$;

$\mathrm{I}_{0}=$ counts in the photopeak area due to the direct photon flux;

$\mathrm{I}=$ counts in the photopeak area due to the transmitted photon flux.

Mathematical rearrangement of Eq. (1) yields to:

$$
\mu=-1 / x \cdot \ln \left(I / I_{0}\right)
$$

The mass attenuation coefficient $(\mu / \rho)$, in $\mathrm{cm}^{2} / \mathrm{g}$, can be calculated by dividing Equation 2 by the sample density: 


$$
\mu / \rho=-1 /(\rho x) \cdot \ln \left(I / I_{0}\right)
$$

2.6 Measurement setup

The measurements were taken place at the Brazilian Ionizing Radiation Metrological Laboratory (LNMRI), at the Institute for Radioprotection and Dosimetry (IRD); the setup consists of a two collimated sources, ${ }^{137} \mathrm{Cs}$ and ${ }^{60} \mathrm{Co}$, two concrete samples, and a $20 \%$ HPGe portable detector positioned at $3 \mathrm{~m}$ distance from the sources. The measurement setup is shown in Figure 1.

The procedure consisted of taking a direct flux $\left(\mathrm{I}^{0}\right)$ measurement from the source and, afterwards, each concrete sample was placed between the source and the detector to account for the transmitted flux (I). The ratio $\mathrm{I} / \mathrm{I}_{0}$ could be calculated for each concrete sample and each photon energy.

Three spectra were taken for each measurement to better account for the direct and transmitted fluxes for each source. The average of the photopeak areas was used for the determination of the linear attenuation coefficient for the concrete samples using to Equation 2. Due to the high activity of the ${ }^{137} \mathrm{Cs}$ and ${ }^{60} \mathrm{Co}$ sources, the photopeak areas uncertainties were kept below $1 \%$.

The radiation attenuation in air was not accounted for due to the fact that the calculations are based on the ratio $\mathrm{I} / \mathrm{I}_{0}$, for both $\mathrm{I}$ and $\mathrm{I}_{0}$ the attenuation is the same and are canceled out.

\subsection{Monte Carlo simulation}

The Monte Carlo method is broadly used for photons and particles transport (Conti et al, 2013; Jacob et al., 1987; Moreira et al., 2010; Salinas et al., 2006; Salgado et al., 2006). It became a powerful tool, very flexible and enables the analysis of a wide energy range. When used together with a spectrometry system, provides means to determine the detector's response function, optimizing both time and financial resources.

The chemical composition of the fibrous self-compacting concrete was calculates by the materials and quantities used for its manufacture. The data used for the computer simulations is presented in Table 1. 
Table 1. Chemical composition of the fibrous self-compacting concrete

\begin{tabular}{cc|cc}
\hline \hline Chemical element & Weight $(\%)$ & Chemical element & Weight $(\%)$ \\
\hline \hline $\mathrm{Si}$ & 29.13 & $\mathrm{Na}$ & 0.35 \\
$\mathrm{O}$ & 52.52 & $\mathrm{Ti}$ & 0.07 \\
$\mathrm{Fe}$ & 1.96 & $\mathrm{Mn}$ & 0.04 \\
$\mathrm{Ca}$ & 5.10 & $\mathrm{Ba}$ & 0.01 \\
$\mathrm{~K}$ & 0.21 & $\mathrm{~S}$ & 0.48 \\
$\mathrm{Al}$ & 1.68 & $\mathrm{H}$ & 1.77 \\
$\mathrm{P}$ & 0.01 & $\mathrm{C}$ & 1.55 \\
$\mathrm{Mg}$ & 0.28 & $\mathrm{~N}$ & 4.85 \\
\hline \hline
\end{tabular}

Based on the experimental mass attenuation coefficients determination set up, as shown in Figure 1, a set simulation by the Monte Carlo of the concrete sample was carried out. The experimental results were compared to the Monte Carlo simulations for validation of its procedure.

Figure 1. The experimental setup is composed of a collimated detector $20 \% \mathrm{HPGe}$, two collimated source and two concrete samples.

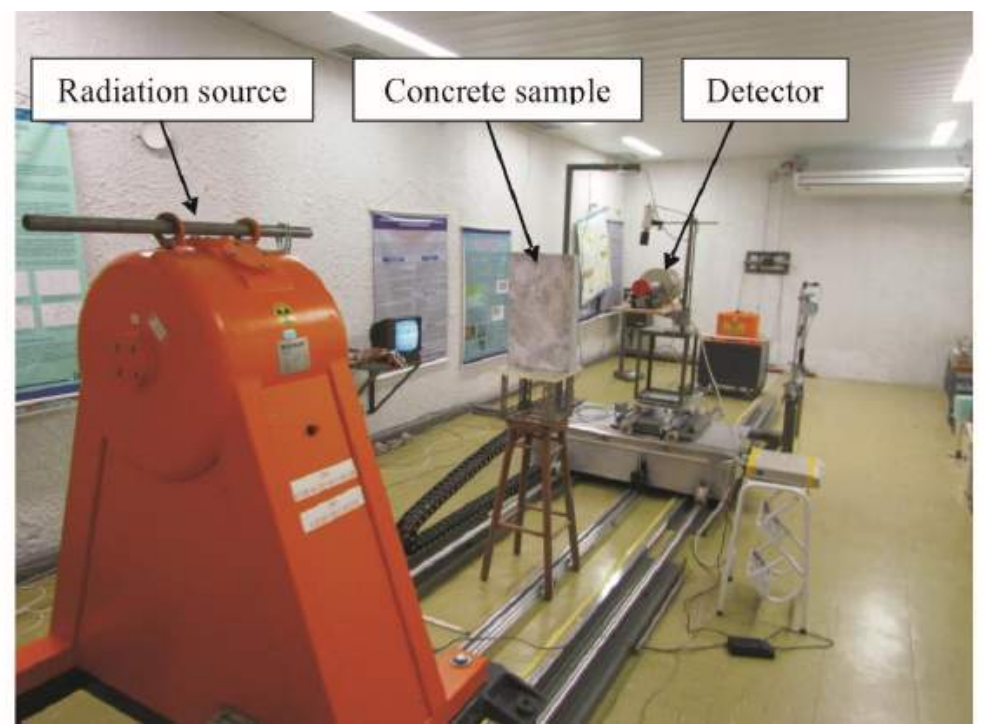




\section{RESULTS AND DISCUSSION}

In order to evaluate the measurement procedure used in this work, ordinary concrete was also measured and the results obtained were compared to the values found in the literature (Hubbell, 1997). The results showed to be in good agreement, therefore, the measurement setup and procedure used could be accepted. Table 2 presents the comparison between the mass attenuation coefficients obtained in this work for ordinary concrete and the values presented in the literature.

Table 2. Comparison between the mass attenuation coefficients obtained in this work for ordinary concrete and the values presented in the literature.

\begin{tabular}{cccc}
\hline \hline $\begin{array}{c}\text { Energy } \\
\mathrm{keV}\end{array}$ & $\begin{array}{c}\text { Ordinary Concrete } \\
(\text { This work }) \\
\mu / \rho\left(\mathrm{cm}^{2} / \mathrm{g}\right)\end{array}$ & $\begin{array}{c}\text { Ordinary Concrete } \\
(\text { Hubbell, 1997) } \\
\mu / \rho\left(\mathrm{cm}^{2} / \mathrm{g}\right)\end{array}$ & $\begin{array}{c}\text { Difference } \\
(\%)\end{array}$ \\
\hline \hline 622 & 0.0770 & 0.0788 & 2.3 \\
1172 & 0.0602 & 0.0600 & -0.3 \\
1332 & 0.0576 & 0.0562 & -2.5 \\
\hline \hline
\end{tabular}

The densities of the samples used were found to be $1.9 \mathrm{~g} / \mathrm{cm}^{3}$ for ordinary concrete and $2.4 \mathrm{~g} / \mathrm{cm}^{3}$ for the fibrous self-compacting concrete. Table 3 shows the values of the mass attenuation coefficients for both ordinary and fibrous self-compacting concrete.

Table 3. Mass attenuation coefficients for both ordinary and fibrous self-compacting concrete and the difference when compared to ordinary concrete.

\begin{tabular}{cccc}
\hline \hline $\begin{array}{c}\text { Energy } \\
(\mathrm{keV})\end{array}$ & $\begin{array}{c}\text { Ordinary Concrete } \\
\mu / \rho\left(\mathrm{cm}^{2} / \mathrm{g}\right)\end{array}$ & $\begin{array}{c}\text { Fibrous self-compacting concrete } \\
\mu / \rho\left(\mathrm{cm}^{2} / \mathrm{g}\right)\end{array}$ & $\begin{array}{c}\text { Difference } \\
(\%)\end{array}$ \\
\hline \hline 622 & 0.0770 & 0.0814 & 5.7 \\
1172 & 0.0602 & 0.0632 & 5.1 \\
1332 & 0.0576 & 0.0596 & 3.5 \\
\hline \hline
\end{tabular}

It is clear, as expected, that the self-compacting concrete presents higher mass attenuation coefficients than ordinary concrete and, also, the difference increases as the energy decreases. Nevertheless, when considering the effect of the density in the overall gamma ray shielding, the difference between ordinary and fibrous self-compacting concrete can be much greater, reaching about $46 \%$ in the transmitted flux for a $662 \mathrm{keV}$ gamma flux and a $10 \mathrm{~cm}$ thick concrete slab. The calculated transmitted flux and differences are presented in Table 4. 
Table 4. Normalized transmitted $662 \mathrm{keV}$ gamma flux through a $10 \mathrm{~cm}$ thick slab of ordinary and fibrous self-compacting concrete and the encountered difference.

\begin{tabular}{cccc}
\hline \hline $\begin{array}{c}\text { Energy } \\
\mathrm{keV}\end{array}$ & $\begin{array}{c}\text { Ordinary Concrete } \\
(\mathrm{I})\end{array}$ & $\begin{array}{c}\text { Fibrous self-compacting concrete } \\
(\mathrm{I})\end{array}$ & $\begin{array}{c}\text { Difference } \\
(\%)\end{array}$ \\
\hline \hline 622 & 0.2645 & 0.1418 & 46.4 \\
1172 & 0.3186 & 0.2194 & 31.1 \\
1332 & 0.3347 & 0.2392 & 28.5 \\
\hline \hline
\end{tabular}

Table 5 presents the mass attenuation coefficient for fibrous self-compacting concrete for the 50$3000 \mathrm{keV}$ energy range calculated by the MCNP5 Monte Carlo computer code.

Table 5. Mass attenuation coefficient for fibrous self-compacting concrete for the $50-3000 \mathrm{keV}$ energy range.

\begin{tabular}{cccc}
\hline $\begin{array}{c}\text { Energy } \\
(\mathrm{keV})\end{array}$ & $\begin{array}{c}\text { Fibrous self-compacting con- } \\
\text { crete } \\
\mu / \rho\left(\mathrm{cm}^{2} / \mathrm{g}\right)\end{array}$ & $\begin{array}{c}\text { Energy } \\
(\mathrm{keV})\end{array}$ & $\begin{array}{c}\text { Fibrous self-compacting con- } \\
\text { crete } \\
\left.\mu / \rho \mathrm{cm}^{2} / \mathrm{g}\right)\end{array}$ \\
\hline \hline 50 & 0.387465 & 500 & 0.091893 \\
70 & 0.245579 & 700 & 0.07917 \\
90 & 0.19702 & 1000 & 0.066916 \\
100 & 0.183694 & 1500 & 0.054451 \\
150 & 0.14919 & 2000 & 0.046957 \\
200 & 0.132726 & 2500 & 0.04184 \\
250 & 0.121642 & 3000 & 0.038164 \\
300 & 0.113207 & & \\
\hline \hline
\end{tabular}

The use of fibrous self-compacting concrete as construction material for radioactive facilities can improve greatly the shielding effect of walls and ceiling.

\section{CONCLUSION}

The mass attenuation coefficients for a fibrous self-compacting concrete were determined by transmission measurement for the ${ }^{137} \mathrm{Cs}$ and ${ }^{60} \mathrm{Co}$ gamma emitting energies. The setup and methodology used was verified by the determination of the mass attenuation coefficients for ordinary concrete for the energies of interest and compared to data available in the literature and has proven to be effective. 
The comparison between the mass attenuation coefficients for ordinary and the fibrous selfcompacting concrete showed the later to be as high as $5.7 \%$ and $3.5 \%$, for the lower and higher used gamma energies. These differences are much prominent when considering the material's density. For a $10 \mathrm{~cm}$ concrete slab, the difference in the transmitted fluxes showed to be $46.4 \%$ and $28.5 \%$, for the lower and higher used gamma energies.

The mass attenuation coefficients for fibrous self-compacting concrete were calculated for the 50-3000 keV energy range by the MCNP5 Monte Carlo computer code. The comparison of the data for the three gamma energies from ${ }^{60} \mathrm{Co}$ and ${ }^{137} \mathrm{Cs}$ both calculated experimentally and by MCNP5 showed very good agreement and the calculations have proven to be effective.

The fibrous self-compacting concrete showed a better performance in radiation shielding, and thus, can optimize designs in the field of radiation protection.

\section{REFERENCES}

AKKURT, I.; KILINCARSLAN, S.; BASYIGIT, C. The photon attenuation coefficients of barite, marble and limra. Ann. Nucl. Energy, 31, p.577-582, 2004.

ALAN, M.; MIAH, M.; CHOWDHURY, M.; KAMAL, M.; GHOSE, S.; RAHMAN, R. Attenuation coefficients of soils and some building materials of Bangladesh in the energy range 2761332keV. Appl. Radiat. Isot., 54, p.973-976, 2001.

CONTI, C.; SALINAS, P.; ZYLBERBERG, H. A detailed procedure to simulate an HPGe detector with MCNP5. Prog. Nucl. Energy, v. 66, p. 35-40, 2013.

FACURE, A.; SILVA, A. The use of high-density concretes in radiotherapy treatment room design. Appl. Radiat. Isot., 65(9), p. 1023-1028. DOI:10.1016/j.apradiso.2007.04.006, 2007. 
HUBBELl, J.; SELTZER, S. Tables of X-Ray Mass Attenuation Coefficients and Mass Energy-Absorption Coefficients (version 1.03). [Online] Available: http://physics.nist.gov/xaamdi [2004, July 26]. National Institute of Standards and Technology, Gaithersburg, MD, 1997.

JACOB, P.; MECKBACH, R. Shielding factors and external dose evaluation. Radiat. Prot. Dosim., Vols. 21, n. 1-3, p. 79-85, 1987.

MARAGON, E. Development and characterization of self-compacting Concrete reinforced with steel fibers. Dissertation, COOPE / Federal University of Rio de Janeiro, Rio de Janeiro, 128 p, 2006.

MARAGON, E. Development and characterization of self-compacting Concrete reinforced with steel fibers. Thesis, COOPE / Federal University of Rio de Janeiro, Rio de Janeiro, 2009.

MOREIRA, M.; CONTI, C.; SCHIRRU, R. A new NaI(Tl) four-detector layout for field contamination assessment using artificial neural networks and the Monte Carlo method for system calibration. Nucl. Instr. Meth. Phys. Res. A, vol. 621, p. 302-309, 2010.

SALINAS, I.; CONTI, C. LOPES, R. Effective density and mass attenuation coefficient for building material in Brazil. Appl. Radiat. Isot., 64, p. 13-18, 2006.

SALGADO, C.; CONTI, C.; BECKER, P. Determination of HPGe detector response using MCNP5 for 20 - 150keV X-rays. Appl. Radiat. Isot., p. 700 - 705, 2006. 